\title{
Erratum: U2AF-homology motif interactions are required for alternative splicing regulation by SPF45
}

Lorenzo Corsini, Sophie Bonnal, Jerome Basquin, Michael Hothorn, Klaus Scheffzek, Juan Valcárcel \& Michael Sattler Nat. Struct. Mol. Biol. 14, 620-629 (2007); published online 24 June 2007; corrected after print 2 July 2007

In the version of this article initially published, the name of the second author, Sophie Bonnal, was misspelled. The error has been corrected in the HTML and PDF versions of the article. We apologize for this error. 